\title{
Global Burden of Non-communicable Diseases:Preparedness of Bangladesh to Combat the Menace
}

Md. Nurul Amin 1

Non-communicable diseases (NCDs) are now the leading causes of morbidity and mortality worldwide. ${ }^{1}$ According to the Global Burden of Disease study, NCDs were responsible for the deaths of 38 million people in $2013^{2}$ accounting for $63 \%$ of annual global deaths; most of them were preventable. $^{3}$ Forty-two percent of NCD deaths occurred among people under 70 years of age and of those deaths, $82 \%$ were in the low- and middle-income countries (LMICs). The estimated 2010 global cost of NCDs was $\$ 6.3$ trillion (US dollars), which is projected to increase to $\$ 13$ trillion by 2030.4 Countries accross the world recognize that something must urgently be done to alter the current state and future outlook of NCDs. ${ }^{5}$ The burden of NCDs are projected to exceed the combined burden posed by communicable, maternal, perinatal, \& nutritional diseases by 2030 and would emerge as the most common cause of death taking more lives than all other causes combined if appropriate measures are not taken without delay. ${ }^{6}$

Non-communicable diseases share common risk factors related to an unhealthy lifestyle like (1) physical inactivity, (2) unhealthy food behaviour (3) cigarette smoking, which primarily may lead to the development of overweight and obesity, hyperglycemia, dyslipidemia, hypertension and diabetes, all of which, in turn, complexly interact with one another to exponentially increase the risk of ischemic heart disease or stroke.7,8 In 2010, overweight and obesity were estimated to cause 3.4 million deaths worldwide; ${ }^{9}$ the global economic impact of obesity is now approximately $\$ 2$ trillion. ${ }^{10}$ Physical inactivity caused more than 5.3 of the 56 million global deaths in $2008^{11}$ and is currently the fourth leading cause of death worldwide. ${ }^{12}$ Current projections indicate time spent being physically inactive will continue to increase substantially. ${ }^{13}$ Diet quality and dietary patterns (e.g, excess calories and saturated fat) are poor across much of the world and contribute substantially to the NCD burden. 3,14 Smoking also remains as a notable contributor to NCD risk. ${ }^{3,8}$

In order to tackle the burden of NCDs, there is a need for comprehensive, coherent \& multi-sectoral policies and strategies at international, national and local levels. ${ }^{15,16}$ This has already been recognized by the World Health Organization (WHO) in its 2013-2020 Action Plan for the Global Strategy for the Prevention and Control of NCDs. ${ }^{17}$ This action plan has set six objectives for the prevention and control of NCDs. While this has increased awareness regarding the growing burden posed by NCDs and the need for effective policy response, it remains unclear how far it has led to the development and implementation of appropriate policies, particularly in developing countries. ${ }^{18}$ The developed countries, in most cases, have already undertaken broad policy and programmatic analysis to address the challenges posed by the NCDs. However, effective application of such policy in the developing countries including Bangladesh seems to be inadequate. ${ }^{19}$ It may be noted that while more than $70 \%$ of research on the burden of NCDs are conducted in high income countries, low and middle-income countries (LMICs) are home to only $57 \%$ of such researchs. ${ }^{20}$ Nevertheless, seldom such research translates into concrete policy

actions in LMICs. Moreover, there is an acknowledged lack of theoretical and conceptual framework that could be used to design appropriate

\section{Author's information:}

${ }^{1}$ Dr. Md. Nurul Amin, Assistant Professor, Department of Community Medicine, Rajshahi Medical College, Rajshahi \& Executive Editor, Ibrahim Cardiac Medical Journal, Ibrahim Cardiac Hospital \& Research Institute, Shahbag, Dhaka. 
healthy public policy in LMICs. ${ }^{21}$ Like many other developing countries, in Bangladesh as well, non-communicable diseases (NCDs) are emerging as major cause of morbidity and mortality, accounting for $61 \%$ of deaths. ${ }^{22}$ The most common NCDs include cardiovascular diseases, diabetes mellitus, cancer, and chronic respiratory diseases. As the prevalence of these diseases increase, they will impose an even greater burden in the near future. ${ }^{23}$

In response to these emerging trends, the Government of Bangladesh has designed and introduced some innovative initiatives. A substantial number of policy documents have been published to address the critical issues related to the prevention and control of NCDs; however, little effort has been made to conduct a comprehensive analysis of the past and current policy instruments with a view to learn from the experience. A critical appraisal recently done by Biswas et al ${ }^{24}$ suggest that the NCD-related policies introduced in Bangladesh align with the World Health Organization's (WHO) 2013-2020 Action Plan for the Global Strategy for the Prevention and Control of NCDs, but they hardly translated into proper planning, implementation and monitoring. Consequently, over the years Bangladesh had meager success in effectively addressing the growing burden of NCDs.

Of the 51 documents analyzed, seven (13.7\%) were research/survey, nine were on policies $(17.7 \%)$, while seventeen $(33.3 \%)$ were on action plans. On the other hand, five $(9.8 \%)$ and thirteen $(25.5 \%)$ were related to guidelines and/or strategic plans/documents respectively from government institutes and non-government institutes. The National Strategic Plan for Surveillance and Prevention of Non-Communicable Diseases in Bangladesh 2007-2010, the first strategic plan for prevention of $\mathrm{NCDs}^{25}$ highlighted several action plans such as for hospital based surveillance, inpatient NCD surveillance in specialized institutes, and monthly reporting of morbidity and mortality attributable to NCDs, as well as inpatient surveillance in medical college, district, and upazila hospitals, review meetings, publication of newsletters, reports, capacity building of the human resources and strengthening of information technology (IT) for the improvement of recording and reporting. ${ }^{24}$

There was some evidence of building collaborative efforts for NCD prevention and control through partnership nurtured by UN agencies, other international organizations and NGOs. For strengthening health care system in Bangladesh, government undertook some initiatives. As an innovative initiative, government established the NCD corner in selected Upazila Health Complexes (UHCs) for providing NCD services. In Bangladesh not only the government but also some international and national research centers such as the International Center for Diarrhoeal Disease Research, Bangladesh (icddr,b), Bangladesh Rural Advancement Committee (BRAC), Bangabandu Sheike Mujib Medical University (BSMMU), the Global Health Institute of the North South University, and EMINENCE, are also involved in research related to NCDs. ${ }^{24}$

To reduce modifiable risk factors for noncommunicable diseases and underlying social determinants through health promotion, there are twenty-three documents. The first is the "Smoking and Tobacco Products Usage (Control) Act" of 2005. In order to further strengthen it, the Act was amended in 2013. This act highlighted few actions such as, ban on tobacco product advertisement, warning signs on the packaging of tobacco products, controlling the cultivation of tobacco, demotivating establishment of new industries related to tobacco products, ban on purchase and sale of tobacco products to the underaged (below the age of 18), ban on smoking in public places and while commuting on a public transport. In March 2016, Bangladesh introduced larger graphic warning signs on all tobacco packages. ${ }^{24}$

In response to the findings of the National NCD Risk Factor Survey 2011, the health care system of Bangladesh took some initiatives to combat chronic non-communicable diseases. The National NCD plan is a notable one of them. Under this Plan a dedicated unit titled Non-Communicable Diseases Centre (NCDC) with dedicated line director has 
been established within the Ministry of Health and Family Welfare. With a view to bring NCD services to the doorstep of the people, one of the key initiatives was the introduction of NCD corner in Upazila Health Complexes (UHCs), first piloted in 2012, with the introduction of three NCD corners in three UHCs in the south-western districts of Khulna Division. ${ }^{26}$ Since then, the Government of Bangladesh has taken commendable steps to expand the NCD corners to 300 UHCs throughout the country.

To promote and support national capacity for high-quality research, Director General of Health services (DGHS) in Bangladesh has been empowered to invest in NCD related research. There are also several other national public health research institutes such as Institute of Public Health, the Institute of Public Health Nutrition, the National Institute of Preventive Medicine, the National Institute of Population Research and Training (NIPORT), BSMMU, the National Institute of Cardiovascular Diseases (NICVD) etc. But due to lack of skilled researchers, in these institutes have not yet been able to make any commendable contribution to this field. However, to monitor the trends and determinants of non-communicable diseases and evaluate progress in their prevention and control, the DGHS, in 2010, conducted the first National survey on NCDs and their risk factors. The survey revealed prevalence of hypertension to be $17.9 \%$ in general $(18.5 \%$ in men and $17.3 \%$ in women), the prevalence of self-reported or documented DM to be 3.9\% (men $4.3 \%$ and women $3.6 \%)$. A systematic review and meta-analysis between 1995 and 2010 showed that the prevalence of diabetes among the adults in Bangladesh has increased significantly during the period, $4 \%$ in $1995-2000,5 \%$ in 2001-2005, and $9 \%$ in 2006-2010,27 while the first, nationally representative study in Bangladesh demonstrated the prevalence of prediabetes and diabetes to be 23 and $10 \%$ respectively indicating that the disease has attained an epidemic status. ${ }^{28}$ Tobacco consumption is quite common in Bangladesh: prevalence is $51.0 \%$ for any form, $26.2 \%$ for smoking and $31.7 \%$ for smokeless tobacco. ${ }^{29}$ Studies exclusively related to dyslipidemia are sparse in Bangladesh. In a study involving secretariat employees in Dhaka, abnormal fasting total cholesterol (TC), LDL-C, HDL-C and TG were found to be $17.3 \%, 48.5 \%, 75.6 \%$ and $48.5 \%$, respectively. ${ }^{30}$ A very recently published study ${ }^{31}$ involving 51,353 people predominantly urban resident, demonstrated significantly higher mean serum levels of TC, LDL-C, TG, LDL to HDL ratio and TC to HDL ratio among younger adults aged 30-39 years compared to other age groups, regardless of sex. A series of NCD-related surveys have so far been undertaken with financial/ technical support from sevaral international agencies such as the World Health Organization (WHO) \& the Japanese International Cooperation Agency (JICA). Moreover, the first nationwide health facility survey in Bangladesh identified and described the health facilities available for NCD services in the country. But the findings gleaned from these studies, which among others also included the nutritional status and unhealthy behavior of children, that all these efforts have not effectively addressed the issue of NCDs.

Thus, it is evident that Government of Bangladesh has taken numerous of initiatives to combat NCDs. However, effective enforcement of these policies and acts remains problematic. Close monitoring and supervision of the system is lacking making it difficult to ensure proper implementation of these policies at the root level. A multi-sectoral approach is also lacking that could maximize the positive output of these policies and acts. With a view to promote health and prevent NCDs through physical exercise, WHO outlined various guidelines for creating opportunities for games and physical activities in educational institutions. ${ }^{33}$ Unfortunately, educational institutions in Bangladesh, especially in urban areas, lack of adequate space or playground for physical activity. The National Sports Policy also emphasized establishing and maintaining open space or fields in all educational institutions. Again, the policy seems to be poorly implemented, as $18.2 \%$ of secondary school children of a rural area (Puthia, Rajshahi) was found overweight or obese in a recent study (Life-style Practice among Secondary School Children with Particular Emphasis to Physical 
Exercise and Diet, 2019 unpublished document). There are also directions to establish sports facilities, swimming pools and gymnasium in educational institutions - from village to the city level. However, little attention is being paid to operationalize these directives. Agricultural policy clearly emphasized the need to diversify the agriculture sector and produce agricultural products with higher quality of nutrition to satisfy the nutritional needs of the general population. However, in this case too there are no clear directions in ensuring the availability of fresh vegetables and fruits for the city dwellers. ${ }^{24}$ Recentlya study titled "A scorecard for tracking actions to reduce the burden of non-communicable diseases" reported that among the four domains of governance, risk factor surveillance, research, and health system response, the performance score Bangladeshs was low in three domains, except for the governance domain (moderate performance). ${ }^{34}$ It means that although the government initiated many policies or programs, there is a clear lack of rigorous implementation and monitoring of these policies \& programs. On the other hand, the country lacks any integrated community public health program focused on monitoring NCDs on a regular basis. Bangladesh also lacks any national surveillance program focused on NCDs. Unfortunately, only a few tertiary hospitals maintain such NCD surveillance systems. ${ }^{35}$ Needless to say, had policies and programs adopted by Bangladesh Government to control NCDs been implemented plan-wise, a much better outcome could have resulted despite the resource-poor context of Bangladesh.

\section{References:}

1. Bloomfield GS, Xavier D, Belis D, Alam D, Davis P, Prabhakaran $\mathrm{D}$, et al. Training and capacity building in LMIC for research in heart and lung diseases: the NHLBI-United Health Global Health centers of excellence program. Glob Heart 2016;11(1):17-2.

2. Naghavi $M$, Wang $H$, Lozano $R$, Davis $A$, Liang $X$, Zhou $M$, et al. Global, regional, and national age-sex specific all-cause and cause-specific mortality for 240 causes of death, 1990-2013: a systematic analysis for the global burden of disease study 2013. Lancet 2015;385(9963):117-71.
3. World Health Organization. Global Action Plan for the Prevention and Control of Noncommunicable Diseases: 2013-2020. Geneva, Switzerland: WHO Press; 2013. http://www.who.int/global-coordination-mechanism/p ublications/global-actionplan-ncds-eng.pdf (15 May 2015).

4. Atun J, Jaffar S, Nishtar S, Knaul MF, Barreto ML, Nyirenda $\mathrm{M}$ et al. Improving responsiveness of health systems to non-communicable diseases. Lancet 2013;381:690-97.

5. Geneau R, Stuckler R, Stachenko S, Mc Kee M, Ebrahim S, Basu S et al. Chronic diseases: chronic diseases and development 1 ; raising the priority of preventing chronic diseases: a political process. Lancet 2010;376:1689-698.

6. Alwan A, Armstrong T, Bettcher D, Branca F, Chisholm D, Ezzati M, et al. Global status report on no communicable diseases 2010: description of the global burden of NCDs, their risk factors and determinants. Geneva: World Health Organization; 2011.

7. Mc Gorrian C, Yusuf S, Islam S, Jung H, Rangarajan S, Avezum A et al. INTERHEART Investigators. Estimating modifiable coronary heart disease risk in multiple regions of the world: the INTERHEART Modifiable Risk Score. Eur Heart J 2011;32:581-89.

8. Ng M, Fleming $T$, Robinson $M$, Thomson $B$, Graetz $\mathrm{N}$, Margono $\mathrm{C}$ et al.Global, regional, and national prevalence of overweight and obesity in children and adults during 1980-2013: a systematic analysis for the Global Burden of Disease Study 2013. Lancet 2014;384:766-81.

9. Mc Kinsey Global Institute. Overcoming Obesity: An Initial Economic Analysis. New York, NY: Mc Kinsey and Company; 2014.

10. Lee IM, Shiroma EJ, Lobelo F, Puska P, Blair SN, Katzmarzyk PT. Lancet Physical Activity Series Working Group. Effect of physical inactivity on major noncommunicable diseases worldwide: an analysis of burden of disease and life expectency. Lancet 2012;380:219-29.

11. Kohl HWIII, Craig CL, Lambert EV, Inoue S, Alkandari $J R$, Leetongin $G$ et al. Lancet Physical Activity Series Working Group. The pandemic of physical inactivity: global action for public health. Lancet 2012;380:294-305.

12. Ng SW, Popkin BM. Time use and physical activity: a shift away from movement across the globe. Obes Rev 2012;13:659-80.

13. Krebs-Smith SM, Guenther PM, Subar AF, Kirkpatrick SI, Dodd KW. Americans do not meet federal dietary recommendations. J Nutr 2010;140:1832-38.

14. Go AS, Mozaffarian D, Roger VL, Benjamin EJ, Berry JD, Blaha MJ et al. American Heart Association Statistics Committee and Stroke Statistics Subcommittee. Heart 
disease and stroke statistics-2014 update: a report from the American Heart Association. Circulation 2014;129:e28-e292.

15. World Health Organization. Health policy. Geneva: World Health Organization; 2013. Available at: http://www.who.int/topics/health_policy/en/ . Accessed 11 Feb 2013. Accessed 01 March 2017.

16. Bonita R, Magnusson R, Bovet $\mathrm{P}$, Zhao D, Malta DC, Geneau R, et al. Country actions to meet UN commitments on non-communicable diseases: a stepwise approach. Lancet 2013;381(9866):575-84.

17. World Health Organization. Global action plan for the prevention \& control of no communicable diseases 2013-2020. Geneva: World Health Organization; 2013. http://apps.who.int/iris/bitstream/10665/94384/1/9789241506236_eng.pdf. Accessed 01 March 2017.

18. Walt G, Gilson L. Reforming the health sector in developing countries: the central role of policy analysis. Health Policy Plan 1994;9(4):353-70.

19. Walt \& Gilson, 1994, Gilson L, Raphaely N. The terrain of health policy analysis in low and middle income countries: a review of published literature 1994-2007. Health Policy Plan 2008;23(5):294-307.

20. Walt G, Gilson L. Can frameworks inform knowledge about health policy processes? Reviewing health policy papers on agenda setting and testing them against a specific priority-setting framework. Health Policy Plan 2014;29(suppl 3):iii6-iii22.

21. World Health Organization. Assessing national capacity for the prevention \& control of no communicable diseases. Report of the 2010 global survey. Geneva: World Health Organization; 2013. http://www.who.int/chp/ncd_capacity/NCD_CCS_2013 _report.pdf?ua =1. Accessed 01 March 2017.

22. Habib SH, Saha S. Burden of non-communicable disease: global overview. Diabetes Metab Syndr 2010;4(1):41-7.

23. Alam D, Robinson $H$, Kanungo A, Hossain MD, Hassan M. Health Systems Preparedness for responding to the growing burden of non-communicable disease-a case study of Bangladesh. Melbourne: Place? : Nossal Institute for Global Health; 2013. p.1-25. Available at: http://ni.unimelb.edu.au/-data/assets/pdf_file/0008/7 20656/WP25.pdf. Accesses 01 March 2017.

24. Biswas $T$, Pervin S, Tanim MIA, Niessen L, Islam A. Bangladesh policy on prevention and control of non-communicable diseases: a policy analysis. BMC Public Health BMC series - open, inclusive and trusted2017;17:582https://doi.org/10.1186/s12889-0 17-4494-2.

25. Bangladesh. Ministry of Housing \& Public Works. Preparation of Detailed Area Plan (DAP) for DMDP. Dhaka: Ministry of Housing \& Public Works, Bangladesh; 2010. Available at: http://www.
rajukdhaka.gov.bd/rajuk/image/dap/groupD_Report/p artE/location10/Chapters_10.pdf].

26. Alam $D$, Robinson $H$, Kanungo $A$, Hossain MD, Hassan M. Health Systems Preparedness for responding to the growing burden of non-communicable disease-a case study of Bangladesh. Melbourne: Place? : Nossal Institute for Global Health 2013. p.1-25. Available at: http://ni.unimelb.edu.au/_data/assets/pdf_file/0008/ 720656/WP25.pdf. Accesses 01 March 2017.

27. Saquib N, Saquib J, Ahmed T, Khanam MA, Cullen MR. Cardiovascular diseases and type 2 diabetes in bangladesh: a systematic review and metaanalysis of studies between 1995 and 2010.Bmc public health 2012;12:434. Doi: http://dx.doi.org/10.1186/1471-2458-12-434 pmid:22694854.

28. Akter S, Rahman MM, Abeb SK, Sultana P. Prevalence of diabetes and prediabetes and their risk factors among Bangladeshi adults: a nationwide survey.Bull World Health Organ2014;92:204-213A. doi: http://dx.doi. org/10. 2471/BLT.13.128371.

29. World Health Organization. Non-Communicable Disease Risk Factor Survey Bangladesh 2010. [cited 2013 Jul 3]. Available from: http://www.ban.searo.who.int/LinkFiles/Publication_N CD_Risk_Factor_Survey_Report.pdf.

30. Alam MB, Ahsan HAMN, Islam MZ Pattern of lipid profile and obesity among secretariat employees of Bangladesh. J Med 2009;10:3-6.

31. Das SK, Faruque ASG, Chowdhury AK. Lipoprotein status among urban populations in Bangladesh. Atherosclerosis 2012;223:454-57.

32. Bangladesh, Ministry of Health and Family Welfare. An act for the amendment of smoking and tobacco products usage (control) act. Dhaka: Ministry of Health and Family Welfare; 2005. https://www.tobaccocontrollaws.org/files/live/Bangladesh/Bangladesh\%20-\%20TC\%20Amdt.\%20Act\%202013.pdf. Accessed 01 March 2017].

33. Bull FC, Pratt M, Shepherd RJ, Lankenau B. Implementing national population based action on physical activity-for action and opportunities for international collaboration. Promot Educ 2006;13(2):127-32.

34. Roman AV, Perez W, Smith R. A scorecard for tracking actions to reduce the burden of non-communicable diseases. Lancet 2015;386(9999):1131-2.

35. El-Saharty S, Ahsan KZ, Koehlmoos TL, Engelgau MM. Tackling noncommunicable diseases in Bangladesh: now is the time. Washigton DC: World Bank; 2013. 